\title{
From prescription to addiction: a study of prescription drug abuse
}

\begin{abstract}
General practitioners are dispensing an increasing number of painkillers to their patients at a time when drug abuse is rife in Britain's prisons and addiction to prescription drugs is in the headlines due to the fall from grace of a high-profile celebrity. This study seeks to investigate how widespread the abuse of prescription drugs has become and what possible solutions there may be. It will examine which drugs are most widely abused and the role of prescription drugs as a more easily obtainable source of illicit highs in the prison population. It will consider what action needs to be taken as a result. The study indicates that pregabalin and gabapentin are drugs most widely abused within the prison population and that drugs are being dispensed with too little consideration of their addictive properties. It is concluded that further research into this area is required with consideration of possible changes to the law in relation to which drugs are controlled, but acknowledges the difficulties due to the medicinal benefits and large numbers of NHS patients currently reliant on these drugs, and underfunding of alternative services such as cognitive behavioural therapy (CBT) and psychotherapy.
\end{abstract}

Volume 7 Issue I - 2019

\author{
Andrew O'Hagan, Stephanie Burns \\ Department of Science and Technology Nottingham Trent \\ University UK
}

\begin{abstract}
Correspondence: Andrew O'Hagan, Department of Science and Technology Nottingham Trent University, Clifton Lane, Nottingham NG I I 8NS United Kingdom, Tel +44 I I 58483 I 53 , Email andrew.ohagen@ntu.ac.uk
\end{abstract}

Received: February 05, 2019 | Published: February 19, 2019

Keywords: addiction, pregabalin, gabapentin, prison

\section{Introduction}

It is currently estimated that around two million people in the United Kingdom have an addiction of some sort. This means that they cannot control their usage of the addictive practice and are indulging in it to the extent that it could be harmful to them. ${ }^{1}$ According to the National Institute on Drug Abuse, addiction is a chronic condition, and is defined as a brain disease due to the fact that drugs alter the structure and function of the brain. These alterations can result in negative behaviours that are damaging to the abuser's well-being. ${ }^{2}$ Research has shown, that in 2015, one in eleven patients in the NHS were being prescribed a potentially addictive, or dependence forming prescription medication. ${ }^{3}$ This review considers the area of prescription drug addiction and will seek to ascertain which prescription drugs are most likely to cause addiction and whether there needs to be a change in the law relating to prescription drugs. This may lead to questions about the ease with which the medical profession dispenses these drugs, and whether drugs commonly given for relief of pain, anxiety, and depression should be controlled more strictly. There also needs to be investigation into the legal position in relation to drug classification and prosecution for possession, use, and distribution. The review will look into what kind of people are taking prescription drugs to excess, and how readily available these drugs are; taking into account the numbers of prescriptions being issued under the NHS and online. It will look into whether people are sharing prescription drugs which have been prescribed for their use alone and the ease of access to drugs within the home, such as that which has led to the so called "Pharm parties" in the US. ${ }^{4}$ These parties involve teenagers taking drugs from the family medicine cabinet leading to mixing of a variety of pharmaceutical compounds, not intended to be taken together. It will look at the way that people can progress from legitimate use of drugs to control symptoms, to dependence upon them. This paper will seek to ascertain whether prescription drugs should be more tightly controlled, and more use made of psychological support, in order to combat the current increase in abuse of prescription drugs and resultant harm to their users. It will investigate whether a change is needed in legislation in order to prevent the misuse of prescription drugs as it causes not only harm to individuals but is also a drain on the already stretched resources of the NHS.

\section{Discussion}

\section{Where addiction begins}

People are prescribed drugs in the first instance to deal with an immediate problem, such as pain or anxiety. These problems can be long term, in which case the patient may develop a tolerance to the drug with which they are being treated. Koob and Lee Moal suggest that a person's body will attempt to counteract the effect of a drug whereby the point at which effectiveness is achieved continually changes, as the therapeutic dose increases. ${ }^{5}$

This in turn means patients develop dependence leading to symptoms of withdrawal if they stop taking the drug. Addiction to a prescription drug may be more common where people have a previous addiction, for example to alcohol, or who are severely depressed. ${ }^{6}$ One reason why people may be more likely to become addicted to prescription drugs is because people consider them to be safe because they are prescribed by a medical practitioner. ${ }^{7}$ Addiction may also occur where people have taken prescription drugs prescribed to others. Patients may give drugs to family members, for example to treat acute pain like toothache, or they may be stolen from relatives as with the Pharm parties or sold by patients to drug users for profit. Although it may be suggested that long term use leads to addiction, there are also suggestions that this can be a much faster process. According to a study on onset and perceived addiction carried out in the city of Lean, the school students identifying themselves as users of codeine cough syrup believed that addiction started during their initial consumption Table $1 .{ }^{8}$ Prescription drugs work in very similar ways to illegal drugs; for example, opioid pain relievers attach to the same cell receptors as heroin - which is prescribed by doctors in the form of diamorphine; (a purer version of heroin) to patients with severe pain, - and prescription depressants work in a similar way to GHB. Diamorphine, in addition to easing pain gives a sense of euphoria to the user. It is twice as strong as morphine however addicts may be able to take ten times 
the usual lethal dose before being affected. Patients who are given diamorphine for pain may eventually build up a tolerance which can lead to dependence upon it. If the diamorphine is then no longer prescribed, the patient is likely to suffer withdrawal symptoms which may lead to them seeking to obtain further supplies of this drug illegally, and so purchasing heroin on the streets. ${ }^{9}$ All of these drugs cause an increase in the amount of dopamine in the brain leading to heightened pleasure, which can ultimately result in addiction. ${ }^{10}$ Drugs such as fentanyl bind to opioid receptors found on nerve cells; stimulants like Ritalin, prescribed for ADHD, cause a build-up of dopamine and norepinephrine; and drugs such as Valium act as central nervous system depressants. Opioids, stimulants and depressants all increase the amount of dopamine. ${ }^{11}$ Dopamine is involved in controlling arousal and higher levels of dopamine will increase energy and decrease fatigue. It is also important in the motivation system, and dopamine increases naturally due to pleasurable experiences, and the rise in dopamine reinforces the desire to repeat the actions. The result of this is that addictive drugs will use this system of motivation, leading to the addict requiring more of the drug. Long term use of prescription drugs of this nature will eventually lead to the brain seeing the drug as not just therapeutic, but necessary for survival. ${ }^{12}$

Table 1 Prisoner survey responses (adult men): diversity analysis ${ }^{14}$

\begin{tabular}{lll}
\hline Year 2016/17 & $\begin{array}{l}\text { Black and ethnic } \\
\text { minority (\%) }\end{array}$ & White (\%) \\
\hline $\begin{array}{l}\text { Currently taking medication } \\
\begin{array}{l}\text { Developed a drug problem since } \\
\text { entering prison }\end{array}\end{array}$ & 41 & 57 \\
$\begin{array}{l}\text { Developed a diverted medication } \\
\text { problem since entering prison }\end{array}$ & 6 & 93 \\
$\begin{array}{l}\text { Entered prison with an existing drug } \\
\text { problem }\end{array}$ & 21 & 32 \\
$\begin{array}{l}\text { Found it easy to obtain illegal drugs } \\
\text { in prison }\end{array}$ & 40 & 49
\end{tabular}

Responses of prisoners to questioning about their drug taking habits and access to drugs in prison.

\section{Prescription drugs in prisons}

There has been much discussion in the press about the state of British prisons and the fact that drugs are readily available within prison. Many inmates are in prison due to an existing drug habit either because they have been caught in possession of drugs or have been involved in crime in order to fund a drug addiction. While illegal drugs may make their way into prison it is clear that prescription drugs, either smuggled in by relatives or obtained from prison medics, are another source to satisfy the addiction. As drugs can be used in prison as a form of currency, the temptation must exist for prisoners with a health condition to ask the prison doctor for medication which they then pass on to other prisoners, and to exaggerate their need in order to obtain higher doses. With conditions related to pain it can be very hard for a medical practitioner to prove or disprove the level or authenticity of the pain. Prisoners may become addicted to prescription drugs while in prison which they then continue to abuse on release either by purchasing them from drug dealers or going to their own GP with fabricated symptoms. ${ }^{13}$ Prison overcrowding, poor staff morale and difficulties in recruitment have left prisons with difficulties in management of prisoners' behaviour. Prison inspections have revealed that prison officers are failing to effectively supervise queues of prisoners awaiting medication, leading to chances for prisoners to be bullied and prescription medication into finding its way into the wrong hands. ${ }^{14}$ Table 1 shows that a significant number of people enter prison with a drugs problem, who may be using prescription medication as a substitute for the drugs that they had been taking on the outside. Nearly half of prisoners felt that it was easy to obtain drugs whilst in prison. Most significant for this study, are the figures relating to those who developed a drug problem while in prison, as these can be directly compared to ascertain the role of prescription drugs in new addiction within prison. Looking at the statistics from table 1, it can be seen in black and ethnic minority groups $66 \%$ of the people, who reported developing a drug problem since entering prison, developed the problem with diverted medication, and $69 \%$ in the case of white people. This would suggest that prescription medication has a large role to play in the development of new drug addiction while in prison. The likelihood being that this addiction will continue once discharged from prison leading to a problem in the general population. Once released from prison, prisoners may find it easier to obtain prescription drugs from their own GP who may be less suspicious than a prison doctor. As a result of the fact that they may have made friends in prison they could then become a route by which these drugs are trafficked into prison by visitors, particularly as they would be aware of the value of prescription drugs as a medium of exchange within prison. Use of prescription drugs by prisoners has been highlighted as an issue in HM Prison (HMP) inspection reports for some time. The 2013/14 HMP Annual report stated that 7\% of prisoners had developed a problem with prescription drugs since entering the prison system which equates to around 5900 people. The same report also found that in $50 \%$ of adult male prisons, medication was being taken by people for whom it had not been prescribed. ${ }^{15}$ It is now proposed to look at whether misuse of prescription drugs has increased or decreased in recent years. Looking at Table 1 (20162017) and comparing it to Table 2, (2015-16) it can be see that there has been an increase of $3 \%$ for black and ethnic minorities (BEM) and $5 \%$ for white prisoners taking medication in prison. There has been a $3 \%$ increase in prisoners developing a drug problem on entering prison with an increase of $2 \%$ in prisoners developing a problem with prescription drug misuse. For prisoners entering prison with an existing problem the figures have gone up by $3 \%$ for BEM and $4 \%$ for white prisoners. The ability to obtain illegal drugs in prison has gone up by $11 \%$ for BEM and $8 \%$ for white prisoners. From this it is clear that a higher percentage of prisoners are coming into prison who will seek to find drugs that they need to feed their habit; a higher percentage of prisoners are being prescribed medication while in prison; and a higher percentage of prisoners are developing a drug habit including the use of diverted medication. The fact that a higher percentage of prisoners are reporting that it is easy to obtain drugs in prison could be linked to the fact that more medication is being prescribed and so is more readily available for misuse Table $2 .{ }^{16}$

Of particular interest, when looking at drugs within the prison system are two drugs given for epilepsy and pain relief. Public Health England/ NHS England reported a 46\% rise in prescriptions of gabapentin and a 53\% rise of pregabalin between 2011-2013. Prisoners are twice as likely to be prescribed these drugs as those within the community. In 2013 the Office for National Statistics reported that these two drugs were mentioned on forty-one death certificates. ${ }^{17}$ According to the Centre for Criminal Justice's (CCJ) Drugs in Prisons March 2015 report, ${ }^{18}$ there were five prescription drugs which were highlighted as being the most commonly misused. These were; methadone, buprenorphine, tramadol, gabapentin, and pregabalin. Prisons attempt to avoid the use of drugs by prisoners through the use of drugs testing. Prisoners are tested for the presence of controlled 
drugs (Prison Act 1952 Section 16 A) ${ }^{19}$ and more recently psychoactive substances such as "spice" following the Psychoactive Substances Act $2016 .{ }^{20}$ The drug detection methods used in prison do not however detect the majority of prescription medication which makes it easier for prisoners to abuse the drugs. Tramadol however, has now been reclassified as a controlled drug, and will therefore show up on future tests. ${ }^{15}$ It is likely that this is one of the reasons prescription drug abuse is becoming an ever increasing issue within prisons; as the chances of being caught, and potentially being presented with an extended prison sentence, are lower and therefore prescription drugs may be seen as a "safer" route for prisoners to go down in order to fuel their addiction. It was found that abuse of prescription opiates is widespread in prisons. Existing opiate users, when they are imprisoned, resort to obtaining their drugs through the use of opiates prescribed within the prison setting. The CCJ report found that that in the UK there has been an increase in the prescription of opiate substitution treatment; typically methadone or buprenorphine. It was also found prisoners were obtaining opioids from prison doctors for treatment of physical health problems. As a result of these findings, it has become clear that there is a necessity to find less abusable forms of the medication in question. ${ }^{21}$ Methadone, for example is usually prescribed in the form of an oral suspension; it can also be produced in an injectable form, which is more commonly used when a patient is hospitalised and unable to take it for themselves. If methadone was prescribed in prisons in an injectable form, it would make it impossible for the drug to be concealed for use at a later date, or transferred to another inmate. A major drawback to this solution however, is that a trained physician would need to be available to administer the injections, which would be much more time consuming and costly.

Table 2 Prisoner survey responses (adult men): diversity analysis ${ }^{16}$

\begin{tabular}{lll}
\hline Year 2016/17 & $\begin{array}{l}\text { Black and ethnic } \\
\text { minority (\%) }\end{array}$ & White (\%) \\
$\begin{array}{l}\text { Currently taking medication } \\
\begin{array}{l}\text { Developed a drug problem since } \\
\text { entering prison }\end{array}\end{array}$ & 38 & 52 \\
$\begin{array}{l}\text { Developed a diverted medication } \\
\text { problem since entering prison }\end{array}$ & 4 & 10 \\
$\begin{array}{l}\text { Entered prison with an existing drug } \\
\text { problem }\end{array}$ & 18 & 7 \\
$\begin{array}{l}\text { Found it easy to obtain illegal drugs } \\
\text { in prison }\end{array}$ & 29 & 28 \\
\hline Responses of prisons to question & 41 \\
\hline
\end{tabular}

Responses of prisoners to questioning about their drug taking habits and access to drugs in prison.

\section{Most commonly abused prescription drugs}

An issue has been identified with pregabalin and gabapentin as being abused in prisons; however further research has shown that these two drugs are also emerging as an issue within communities outside of prison as well. These drugs are widely dispensed by the NHS, as shown in Table 3. In 2014 gabapentin was the drug most commonly dispensed for epilepsy and decreased in price in 2015 after a reclassification from category $\mathrm{C}$ to category A. ${ }^{22}$ Prescriptions of pregabalin increased by $350 \%$ and gabapentin by $150 \%$ in the space of five years, leading to concerns being raised by the Advisory Council on the Misuse of Drugs. ${ }^{23}$ The data in Graph 1 shows that between 1993, and 2011 in the Tayside region of Scotland there was an increase in both the number of patients being prescribed gabapentin, and the number of scripts being given out. In 1993, the number of patients and number of scripts were very similar, indicating that on average one patient was getting one script per year; whereas in 2011, there were approximately 7000 patients, receiving 28,000 scripts meaning on average, each patient was receiving four scripts a year. This shows that not only has the number of people taking gabapentin has increased but also the amount of the drug they are taking. ${ }^{24}$ Graph $1 \&$ Table 3. Studies have shown that Pregabalin is more likely to be addictive then gabapentin, however those most at risk of addiction are people with a previous history of substance abuse. Overdosing on gabapentinoids alone does not appear to be dangerous, but mixed with other psychoactive drugs, they became lethal. This has led to recommendations that these should not be administered to addicts or ex-addicts. ${ }^{25}$ while this can be monitored by a patient's GP, there are no such safeguards where someone is taking another person's medication, or where the drug has been illegally purchased. Since January 2016, pregabain and gabapentin have been introduced into the drug screening for corners cases, following the Public Health England Report of 2014. Since this screening began these drugs have been regularly detected, most often in combination with other drugs and often where it was not expected that these would be found. ${ }^{26}$ There also appears to be an increasing problem with the use of gabapentin and pregabalin as recreational drugs being used in combination with heroin. An investigation by the Criminologist Steve Wakeman found that all the heroin users that he spoke to were using these drugs alongside heroin. If heroin is taken alongside gabapentin or pregabalin, less heroin is needed because the drugs boost the effects of the heroin. As prescription drugs are easier to obtain and less expensive than heroin, it is clear to see why there would be an upsurge in the use of these drugs as part of the recreational drug scene. The Drug Scope 2014 street drug survey revealed that in one homeless hostel, $70 \%$ of the people living there were taking pregabalin and gabapentin, but they were not all being prescribed this by their doctors and so were using it recreationally. (17) It has been suggested by the British Medical Journal (BMJ), that an increase in prescriptions for pregabalin and gabapentin correlate to an increase in the number of deaths from overdoses amongst heroin addicts. The use of heroin alongside pregabalin caused blackouts and increased the risk of overdose. $79 \%$ of deaths involving gabapentinoids also involved opioids. ${ }^{27}$ Gabapentinoids were originally designed as drugs to use for epilepsy and somatosensory nerve pain, however it is now being widely used to combat pain of any type; particularly back pain. With these drugs being used to treat a widening number of conditions the number of prescriptions being given out is increasing resulting in a much greater chance of diversion of these drugs occurring. General practitioners appear to be very happy to prescribe drugs for mental health conditions which have the potential for misuse. Although cognitive behaviour therapy is suggested for the treatment of some mental health conditions, the mental health sector is notoriously under staffed and underfunded. This results in patients being given antidepressants as a stop gap treatment. Waiting lists for CBT can be very lengthy leading patients to become reliant on medication because they have been taking it for so long. This is sadly also true for children who should only be prescribed fluoxitine as it is currently the only safe antidepressant for children, but it has been shown that GPs do not always follow the guidelines. Data analysed by Swansea University revealed a $30 \%$ increase in the number of children (aged 6-18) in Wales being prescribed antidepressants; including prescriptions for Citalopram, a drug which is only licenced for use in adults. ${ }^{28}$ The World Health Organisation has shown concern about an increase in Antidepressants for children in the UK, with a study showing a 54\% increase in the number of children prescribed antidepressants between 2005-2012. Comparatively there was a rise of $60 \%$ in Denmark, $49 \%$ 
in Germany, $26 \%$ in the US, and $17 \%$ in the Netherlands in the same time frame. ${ }^{29}$ Long waiting lists for Cognitive Behavioural Therapy are leading to young people being prescribed antidepressants alone, while they wait for therapy. ${ }^{29}$ If children become addicted to antidepressants at a young age this could make them more susceptible to becoming involved in drug misuse as they get into their teenage years and beyond. In an increasingly stressful society, more people are turning to medication as solution to their problems. Social media is often blamed for pressurisation of young people and it would now appear that as well as being the source of anxiety it is also making it easier to access the drugs being used to combat the stress of living. A recent telegraph article revealed that Cambridge university students were using a Facebook forum as a way to obtain prescription drugs. The students were sharing drugs, requesting particular drugs from each other, and offering payment for common antidepressants. Fluoxetine and citalopram were noticeable among the drugs being traded which were among those being given to children by doctors suggesting this may be leading to a dependence in the university years. ${ }^{30}$ In some cases, people were requesting drugs because they claimed to have run out of their own prescribed drugs and needed some to last over a weekend; this demonstrates the addictive nature of the drugs. It is likely that these people would not view themselves as addicted and would not feel that they were doing anything wrong in obtaining a drug they had been given legitimately by their doctor through another source. More importantly, the people supplying the drugs may not consider that people could lie to obtain drugs that have not been prescribed for them or to obtain higher doses to cope with a tolerance. In what may be a seemingly innocent offer of help, they may actually be opening a gateway for addicts to fuel their addiction. It is not only young people who are involved in the addiction to prescription medication; this is just a small proportion of the problem. In Scotland, the use of antidepressants increased by $28.5 \%$ between 2010 and 2015. Two thirds of the people taking them were women, with the majority being in the 50-54 age group. ${ }^{31}$ Prescription drug abuse is not a new problem. A study carried out in London between 1995-1996, found that drug sellers were using a range of methods to obtain drugs not for their own use but to sell to other people. They would target doctors who were more likely to prescribe the drugs without question. They would exaggerate their symptoms; pretend to be someone else; appeal to the sympathetic nature of a doctor; pretend to be addicted; or would claim that they were a visitor to the area in order to obtain drugs. ${ }^{32}$ A 2017 BBC investigation found that prescription medication could be easily purchased from eBay. Undercover reporters were able to obtain Caverject and Enbrel. The person selling the drugs had obtained them free of charge as he was diabetic but was no longer using them, and had three or four regular customers who purchased them off him. The investigation revealed that patients were being prescribed larger quantities than they were actually using themselves and so were able to sell on the surplus. ${ }^{33}$ However, it is not just members of the public who are facilitating taking of drugs not prescribed for the user. In 2016 nine UK pharmacists were banned from practice for illegally selling drugs, including valium, oramorph, and diazepam. ${ }^{34}$ Prescription drugs may be using used either to combat pain and depression where a tolerance has been built up; leading the user to need more of the drug to maintain the relief required, or may be being used to gain a 'high' in the way that a recreational drug user would use some of the 'club drugs' like ecstasy. This can lead to people taking drugs prescribed for people other than themselves either from friends and family or obtained from drug dealers and the internet. It is clear that prescription drugs are widely available, and relatively easily obtained from a number of sources. Large numbers of people are now being prescribed antidepressants on a regular basis, with research showing the United Kingdom having the fourth highest rate of regular antidepressant use in a study of twenty seven countries within Europe, as shown in Graph $2 .{ }^{35}$ There is a case for further investigation to answer the question as to whether it is possible that practitioners are prescribing antidepressants too readily, or if there is a wider reason behind the nations reliance on the medication which needs to be investigated Graph 2. An investigation was carried out across five European countries into self-medication and recreational abuse of prescription drugs. It was found that the most common way to obtain these drugs was sharing between family and friends. $44 \%$ of opioids and $62 \%$ of sedatives were shared this way. In contrast, only $4.1 \%$ of opioids and $2.7 \%$ of sedatives were purchased from internet pharmacies; showing that people sharing drugs that have been prescribed for them was a major issue. This would be much more difficult to do, had they been controlled drugs. If drugs were controlled then people may be more reluctant to give them to family as if discovered, they could be imprisoned. Table 4 shows that Great Britain has the highest rate of non-medical use of Prescription drugs out of the European countries studied ${ }^{36}$ Table 4 \& Table $5 .{ }^{37}$

Table 3 Top 10 Antiepileptic Drugs prescribed by items, 20I $5^{22}$

\begin{tabular}{llll}
\hline $\begin{array}{l}\text { BNF chemical } \\
\text { name }\end{array}$ & $\begin{array}{l}\mathbf{2 0 1 5} \text { items } \\
\mathbf{( 0 0 0 s )}\end{array}$ & $\begin{array}{l}\text { Item difference } \\
(\mathbf{0 0 0 s})\end{array}$ & $\begin{array}{l}\text { Item difference } \\
\mathbf{( \% )}\end{array}$ \\
\hline Gabapentin & 5732 & 744 & 14.9 \\
Pregabalin & 4802 & 715 & 17.5 \\
Sodium Valproate & 2635 & 10 & 0.4 \\
Carbamazepine & 2399 & $(20)$ & -0.8 \\
Lamotrigine & 2226 & 167 & 8.1 \\
Levetiracetam & 1599 & 209 & 15.0 \\
Clonazepam & 893 & 46 & 5.4 \\
Phenytoin Sodium & 848 & $(46)$ & -5.2 \\
Topiramate & 729 & 65 & 9.8 \\
Clobazam & 268 & 18 & 7.2 \\
\hline
\end{tabular}

Prescriptions Dispensed in the Community: Top 10 Antiepileptic Drugs prescribed in the year 2015.

Table 4 Characteristics of EU Meds study, 2014 $4^{36}$

\begin{tabular}{lll}
\hline Country & Percentage (\%) & Total no people \\
Denmark & 12.4 & 2732 \\
Germany & 24.9 & 5511 \\
Great Britain & 25.3 & 5572 \\
Spain & 24.9 & 5507 \\
Sweden & 12.5 & 2748 \\
\hline
\end{tabular}

Comparison of percentage of non-medical use of prescription drugs across 5 European countries.

Table 5 Sentencing for possession/supply controlled substances ${ }^{37}$

\begin{tabular}{llll}
\hline & Class A & Class B & Class C \\
\cline { 2 - 3 } Possession & & & \\
Possession with internet to supply & 7 years & 5years & 2 years \\
& Life sentence & 14 years & 14 years \\
\hline
\end{tabular}

Length of sentences under the Misuse of Drugs Act 197I for the possession and supply of controlled drugs. 


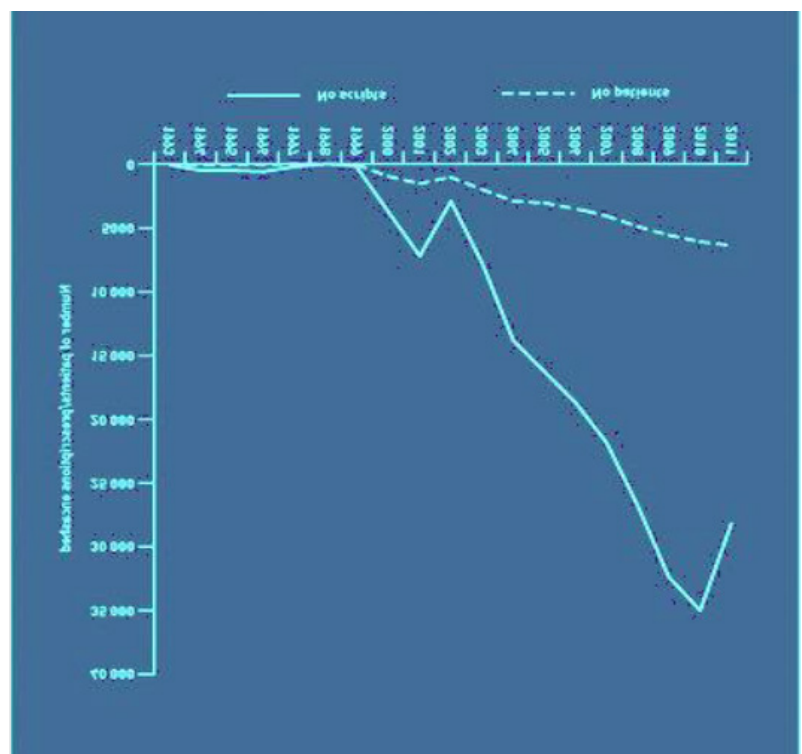

Graph I Prescribing data of gabapentin, in Tayside region of Scotland. ${ }^{24}$ Graph to show the number of scripts and patients prescribed gabapentin for the years 1993-20I I, in the Tayside region of Scotland

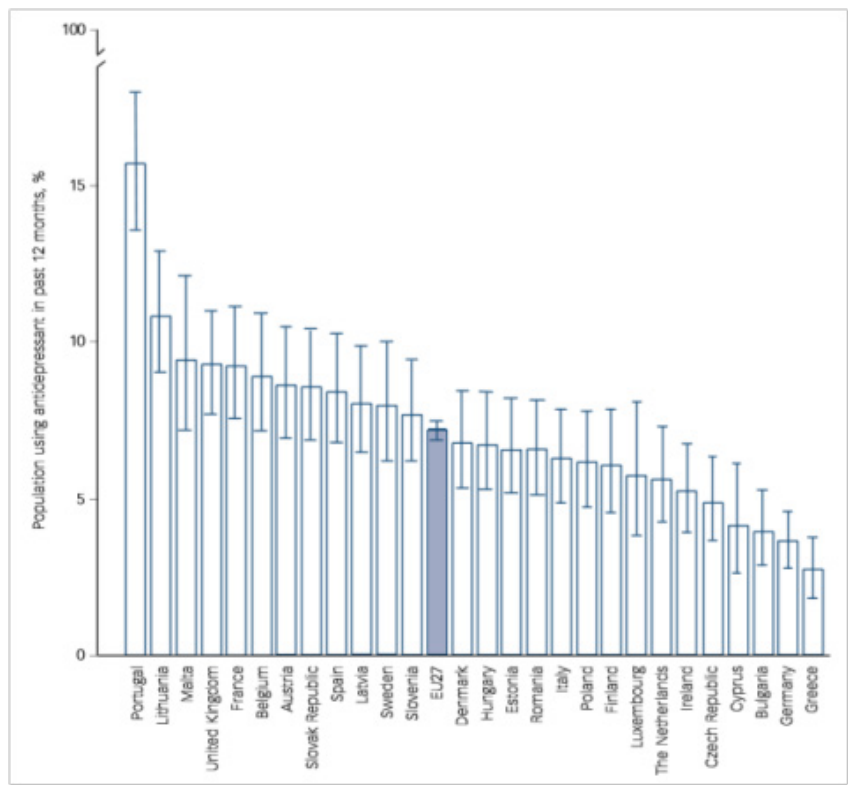

Graph 2 Percentage of 27 EU countries taking antidepressants. ${ }^{35}$

Graph to show the percentage of the population in 27 European countries using antidepressants

\section{Prescription drugs and the law}

The current law relating to prescription drugs is unclear and appears to be open to interpretation. There is no one Act that controls all prescription drugs, which could be part of the reason it is difficult to understand the legal position in relation to prescription drugs. The main body of legislation within the UK which governs the use of drugs, is the Misuse of Drugs Act 1971. This Act however, only regulates controlled drugs, meaning many prescription drugs are not covered by it. There is some crossover in which drugs are both controlled and prescription drugs, for example diamorphine is a Class A drug, codeine is a Class B drug, and diazepam is a Class C drug. If a person is found to be illegally in possession of these controlled drugs they can be subject to a heavy prison sentence. The sentence for supply, or intent to supply is even larger, as demonstrated in table 5. All of the above sentences can be replaced with/or accompanied by a fine. ${ }^{37}$ Whilst this act regulates a number of prescription drugs, there appears to be a gap in the law, where drugs such as gabapentin and pregabalin are concerned, as they are not listed in Schedule II of the Misuse of Drugs Act, or obviously controlled by any other legislation. This means whilst they can only be obtained by consult for the use by an individual named on the prescription there is no obvious legislation to prevent the sharing of these drugs with other people which would lead to a prosecution. It is arguable that a person could be prosecuted under Section 23 of the Offences Against the Person Act 1861, ${ }^{38}$ though this does say that administration of the substance has to be unlawful and malicious. This raises the question of whether it is unlawful to give prescribed drugs to another person, and if there was any intent to cause them harm by doing so. Whilst conducting the research for this paper, it has not been possible to find any definitive legislation referring specifically to the illegality of sharing of prescription drugs which are not classified as controlled drugs, however it is illegal to sell medication without a valid license. The sharing of non-controlled prescription drugs, would appear to be more of a question of morality than legality. From June 10th 2014, tramadol was made a class C drug, under the Misuse of Drugs Act 1971, due to the increased number of deaths related to the drug. ${ }^{39}$ Data has been extracted from the Prescription Cost Analysis published by the $\mathrm{NHS}^{40}$ to show the number of prescriptions given out each January of every year between 2009 and 2017 for three drugs: tramadol, pregabalin, and gabapentin. This information is displayed in Graphs 3-5. It can be seen from Graph 3 that between 2009 and 2014, there was a steady increase in the rise of prescriptions given out, which peaked at 692,321 scripts for the January of 2014. From 2014 (the year tramadol became a controlled drug) to 2017, there has been a fall in the number of prescription drugs given out each year. Tramadol can only be prescribed for twentyeight days and can no longer be prescribed as part of the NHS repeat dispensing scheme. The above data suggests that in making tramadol a controlled drug, general practitioners have become more reluctant to prescribe it so readily, which is likely a contributing factor to the decrease in tramadol related deaths. ${ }^{41}$ Graphs $4 \& 5$ show that there has been a steady increase year on year of prescriptions of these drugs being provided. Since 2009 , there has been a $419 \%$ increase in prescriptions of pregabalin, and a $309 \%$ increase in the prescriptions of gabapentin. It can be estimated, that if prescribing continues to rise at the same rate as over the last three years; then by January 2019, prescriptions of gabapentin will have overtaken tramadol at its highest rate, and by January 2020, pregabalin will have done the same. It is therefore inevitable that before long, pregabalin and gabapentin will appear on more and more death certificates until an intervening factor is introduced, such as making the drugs controlled substances (Graph 3-5).

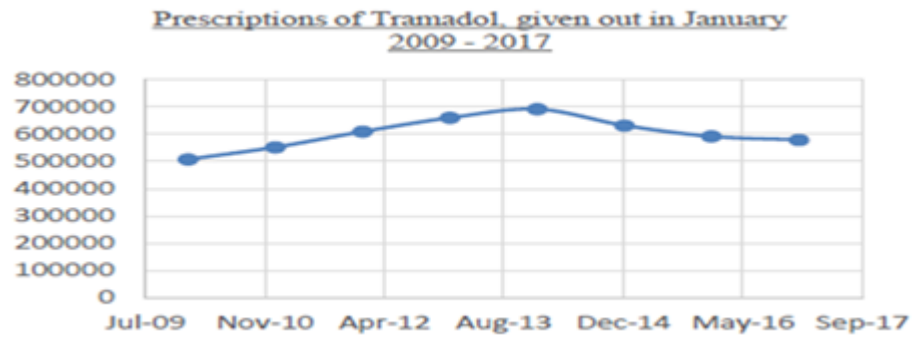

Graph 3 NHS prescribing data: tramadol 2009-2017.40 


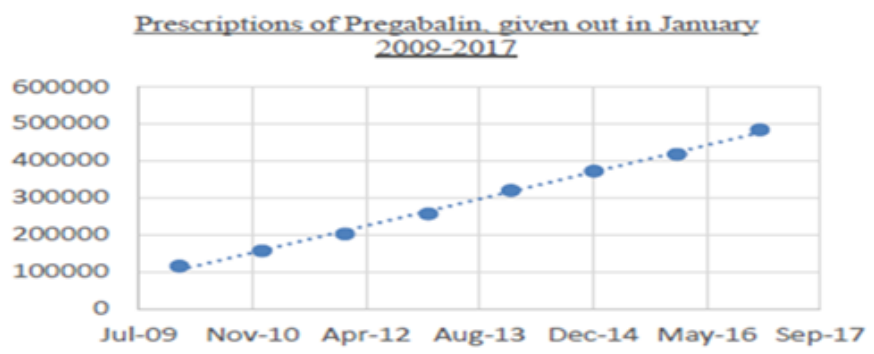

Graph 4 NHS prescribing data: Pregabalign 2009-20I7. ${ }^{40}$

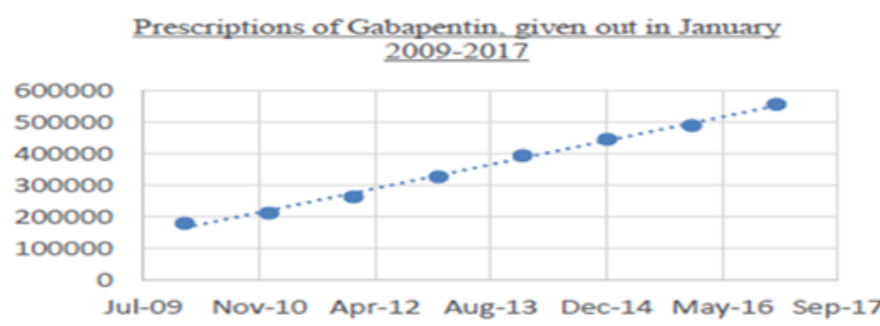

Graph 5 NHS prescribing data: gabapentin 2009-2017.40

\section{Key issues}

The UK Government have recognized that misuse of prescription drugs is an issue. A commons report highlighted the increasing prescription of tramadol, codeine, and other such drugs, as being one of the reasons behind the upsurge in misuse of prescription drugs. ${ }^{42}$ Gabapentin and pregabalin have been identified as major issues in terms of misuse of prescription drugs and suggestions have been made that these should become controlled drugs. The Advisory Council on the Misuse of Drugs felt that the potential harm of these drugs meant that they should be listed as class C substances under the Misuse of Drugs Act $1971 .{ }^{43}$ This suggestion would be supported by the fact that drug related deaths linked to tramadol, an opioid analgesic fell following its reclassification as a class $\mathrm{C}$ drug, under the Misuse of Drugs Act $1971 .{ }^{41}$ It is clear from the areas studied within this paper, that the use and abuse of prescription drugs is an ever-increasing problem. Prescription drugs appear to be readily available and being shared between people for whom they were not prescribed. There is also an issue in that people are lying to practitioners in order to obtain drugs that they don't need, or in larger quantity than they need to supply to others. The misuse of prescription drugs is a serious problem in prisons, which then spills out into the community when prisoners are released. Both inside and outside of prison, gabapentin and pregabalin appear to be the more prevalent choice of prescription drug abuse. A gap in the law has also been identified, as only controlled drugs are currently regulated, whereas the drugs which appear to be being misused are those which are prescribed but do not fall into this category.

\section{Conclusion}

Further research needs to be conducted into just how widespread the issue of prescription drug addiction really is. If the areas in which it was most prevalent could be identified, this would provide a starting point for combatting the problem. It is obvious that legislation must be looked at, even if it just to provide a definitive position on prescription drugs and the law, however reclassification of prescription drugs so that they come under the regulation of the Misuse of Drugs Act would provide a deterrent to the sharing of prescription drugs. While people may be willing to share drugs where it is just a question of a moral choice, the fear of prosecution may prevent them from taking such actions in the future. Legislation is currently in the process of being changed, in order to give prisons the right to test prisoners for drugs which are not currently controlled under the Misuse of Drugs Act $1971 .^{44}$ If screening for drugs such as gabapentin and pregabalin was carried out during mandatory drug testing, it may be possible to identify individuals who may require assistance with an addiction. The issue here however, is that whilst it may show up on drugs tests, there will still be no real deterrent for prisoners to stop taking the prescription drugs. The only way this will change, is if legislation is changed and they become controlled drugs; the taking of which may have an impact upon their sentence. More guidance could be given to General practitioners about the prescribing of drugs likely to be misused, with more careful checks into what and how frequently drugs are given and whether these are necessary if alternative treatment is possible. Another factor in the decrease in tramadol deaths after it was reclassified as class $\mathrm{C},{ }^{41}$ may have been the decrease in the number of prescriptions dispensed in the community and so the ease with which general practitioners prescribe drugs to their patients could be an area of investigation in combatting the misuse of drugs. More funding in the NHS within the area of CBT and mental health could possibly avoid the need for many prescriptions of antidepressants with the associated risks of addiction. Research has shown that doctors sometimes feel they have no other option than to write out a prescription, as the alternative psychological therapies are simply not available, or have too long a waiting list. ${ }^{45}$ More careful monitoring of the internet and social medial could be an avenue for investigation as this appears to be both a source of the stress leading to increased drug taking and a way for addicts to obtain their supplies of prescription drugs. The issue with this however, is that it is simply not possible to monitor all internet platforms. Whilst parents can monitor their children's internet usage to an extent, it would be naïve to suggest they are aware of everything that is happening in the cyber world. Similarly, adults are able to access any page they wish at a click of a button. Whilst website owners themselves are able remove certain pages, on extensive platforms such as Facebook, it is unlikely they will be aware of most of the dangerous pages that exist, without more users reporting them. The impact monitoring these sites could have, is realistically little at best. There is also the question to be asked, whether people are aware that they may be addicted to the drugs they are taking. If more information about addiction was given to service users at the initial point of care, so in this instance, at the same time the prescription is written; it is possible that a person may become aware they are developing an addiction earlier, and so go back to their GP before the problem spirals out of control. Ultimately, the real question that needs to be asked, is would the criminalisation of illegitimate prescription drugs actually help to tackle the overall problem, or would it prevent genuine care users accessing the help they need, for fear of feeling like a criminal? It is possible, that they may compare it to taking heroin or another illicit substance, and therefore be deterred from reaching out to support services to begin with. It must also be considered, that it is illegal to possess controlled drugs, however they are still widely abused regardless of the potential prison sentence that accompanies the abuse. Does legality really make a difference or are the addictive tendencies simply hardwired into a person. It is obvious that something needs to be done with regards to the position of drugs; including both prescription, and non-prescription, but the ultimate question, is what would be the best way forward?

\section{Acknowledgments}

None. 


\section{Conflicts of interest}

The authors declare that there is no conflicts of interest.

\section{References}

1. NHS Choices. Addiction what is it?. 2015

2. National Institute on Drug Abuse. The Science of Drug Abuse and Addiction: The Basics. 2016.

3. Public Health Research Consortium. Prescribing Patterns in Dependence Forming Medicines. 2017.

4. Get Smart About Drugs. Readily Available Prescription Drugs put Teens at Risk. 2017.

5. Cami J, Farrie M. Drug Addiction. The New England Journal of Medicine. 2003;349:975-986.

6. The Royal College of Anesthetists. Taking Opioids for Pain.

7. UK Addiction Treatment Centres. Prescription Drug Addiction.

8. Peters RJ, Kelder SH, Markham CM, et al. Beliefs and Social Norms about Codeine and Promethazine Hydrochloride Cough Syrup (Cphcs) Onset and Perceived Addiction among Urban Houstonian Adolescents: An Addiction Trent in the City of Lean. Journal of Drug Education. 2003;33:415-425.

9. European Monitoring Centre for Drugs and Drug Addiction. Heroin Drug Profile. 2015

10. National Institute on Drug Abuse. Prescription Drugs and Over the Counter Medicines. 2017

11. Michael's House. What Makes Prescription Drugs so Addictive?. 2017.

12. DrugAbuse.Com. Why are Prescription Stimulants so Addictive?

13. BBC three. Prisoners are getting high on cocktails of prescription drugs 2017.

14. GOV.UK. HM Chief Inspector of Prisons for England and Wales Annual Report 2016 to 2017. 2017.

15. Justice Inspectorates. HM Chief Inspector of Prisons for England and Wales Annual Report 2013 to 2014. 2014.

16. Justice Inspectorates. HM Chief Inspector of Prisons for England and Wales Annual Report 2015 to 2016. 2016.

17. DrugWise. Drug link in 2015. 2015

18. Centre for Social Justice. Drugs in Prisons: The Centre for Social Justice Report. 2015.

19. Legislation.gov.uk. Prison Act 1952.

20. Legislation.gov.uk. Psychoactive Substances Act 2016

21. Mohammed Z, Wright MN, Hearty P, et al. Prescription opioid abuse in prison settings: A systematic review of prevalence, practice and treatment responses. Drug and Alcohol Dependence. 2017;171:122-131.

22. NHS Digital. Prescriptions Dispensed in the Community, Statistics for England-2005-2015. 2016.

23. Lacobucci G. UK government to reclassify pregabalin and gabapentin after rise in deaths. British Medical Journal. 2017;358:4441.
24. Smith BH, Higgins C, Baldacching A, et al. Substance misuse of gabapentin. British Journal of General Practice. 2012; 62601:406-407.

25. Bonnet U, Scherbaum N. How addictive are gabapentin and pregabalin? A systematic review. European Neuropsycho pharmacology. 2017;27(12):1185-1215.

26. Nahar LK, Andrews R, Murphy KG, et al. Misuse of gabapentin and pregabalin may be underestimated. British Medical Journal. 2017;359:j5312

27. Wise J. Gabapentinoids should not be used for chronic lower back pain, meta-analysis concludes. British Medical Journal. 2017; 358:j3870.

28. BBC NEWS. $30 \%$ rise in antidepressant prescriptions for children in Wales. 2016.

29. BBC NEWS. Anti-depressants: WHO concern over use by children 2016.

30. The Telegraph. How Cambridge University students are sharing 'dangerous' prescriptions on Facebook. 2016.

31. BBC NEWS. More patients in Scotland given antidepressants. 2015.

32. Fountain J, Griffiths P, Farrell M, et al. Diversion tactics: how a sample of drug misuers in treatment obtained surplus drugs to sell on the illicit market. International Journal of Drug Policy. 1998;9(3):159-167.

33. BBC NEWS. NHS Prescription drugs being sold illegally by patients. 2017.

34. BBC NEWS. Biggest Crackdown on rogue pharmacists. 2016.

35. Lewer D, O'Reilly C, Mojtabai R. Antidepressant use in 27 European countries: Association with sociodemographic, cultural and economic factors. British Journal of Psychiatry. 2015;207(3):221-226.

36. Novak SP, Hakansson A, Martinez-Raga J, et al. Nonmedical use of prescription drugs in the European Union. BMC Psychiatry. $2016 ; 16(274)$.

37. Legislation.gov.uk. Misuse of Drugs Act 1971. 2018.

38. Legislation.gov.uk. Offences against the person Act 1861. 2018.

39. Pharmaceutical Services Negotiating Committee. Controlled Drug changes to the legal classification of Tramadol. NHS Cheshire and Merseyside Commissioning Support Unit. 2014.

40. NHS Business Services Authority. Prescription Cost Analysis (PCA) Data. 2017.

41. Office for National Statistics. Deaths related to drug poisoning in England and Wales: 2016 registrations. Statistical Bulletin. 2017.

42. Publications.parliament.uk. Drugs: new psychoactive substances and prescription drugs. Twelfth Report of Session 2013-14. House of Commons and Home Affairs Committee. 2013.

43. GOV.UK. United Kingdom Drug situation: Focal Point Annual Report 2016. 2017

44. GOV.UK. Criminal Justice and Courts Bill Fact sheet: Drug testing in prisons. 2014

45. The Guardian. Doctors 'forced' to overprescribe antidepressants. 2004 